\title{
Review on Rice Flour Manufacturing and Utilization
}

\author{
Myoung Ho Kim* \\ Department of Bio-industrial Machinery Engineering (Institute of Agricultural Science and Technology), \\ Chonbuk National University, Jeonju, Korea
}

Received: May 20 $0^{\text {th }}, 2013$; Revised: May 26 ${ }^{\text {th }}, 2013$; Accepted: May 26 ${ }^{\text {th }}, 2013$

\section{Abstract}

Background: The Korean government launched a project in 2008, where the amount of rice used as raw ingredient in rice-based foods in 2012 was planned to increase up to $10 \%$ (470,000 ton) of the total rice production through developing various new rice-based processed foods and their commercial manufacturing technology. Among the four major rice-based processed foods, rice cakes and noodles need rice flour as their main raw ingredient. Technology in rice flour utilization and manufacturing is far behind than the technology pertinent to wheat flour in many subject areas. Purpose: This review aims to provide information on rice flour utilization and manufacturing with some fundamental subjects in the area of size reduction. Results: A variety of food items including bread, noodle, cake, cookie, muffin, pre-mix, beverage, vinegar, surimi, and artificial meat have found rice flour as their raw ingredient. Rice bread made out of $100 \%$ rice flour has been developed and is now sold in retail stores. Various noodle products made from rice flour are also on the market. Issues on product definition and labeling regulation about rice flour content of the products were explored. Generalized grinding equations available in the literature were seldom used in practice; instead, it has been a general practice to develop empirical equations from test milling data. Introductory remarks on three popular particle size measurement methods (sieving, Coulter counter, light diffraction) were explained. Mathematical expressions frequently used to describe particle size distribution and to correlate cumulative quantity of particles with particle size were represented. Milling methods used in producing rice flour were described along with their advantages and disadvantages. Because of their profound effect on functional properties of the rice flour, four rice flour milling equipments used at both laboratory experiments and commercial manufacturing plants were discussed.

Keywords: Comminution, Particle size distribution, Rice flour, Rice flour milling, Size reduction

\section{Introduction}

In Korea, domestic rice production has been steady at $4.68,4.84$, and 4.30 million tons in 2006, 2008, and 2012, respectively; however, rice consumption per capita has been dropped from $78.8 \mathrm{~kg}$ in 2006 to $75.8 \mathrm{~kg}$ in 2008 and to $72.8 \mathrm{~kg}$ in 2010 (Anonymous, 2012). Per capita rice consumption has been decreased at a rate of $1.5 \mathrm{~kg} /$ year during last decade and this trend is predicted to continue until a minimum level is reached, which is estimated to be

\footnotetext{
*Corresponding author: Myoung Ho Kim

Tel: +82-63-270-2619; Fax: +82-63-270-2620

E-mail: myoung59@jbnu.ac.kr
}

about $60 \mathrm{~kg}$ (Koh, 2010).

In addition to the disparity in domestic rice supply and demand, mandatory-imported rice based on the minimum market access (MMA) agreement of WTO/DDA (World Trade Organization/Doha Development Agenda) has been further worsening the rice inventory situation. As a result of oversupplied and overstocked rice, the domestic market price of rice has gone down to make rice-growing farmers suffer their decreased income. The Korean government, therefore, launched a project in 2008, where the amount of rice used as raw ingredient in rice- based foods was planned to increase from $6 \%$ (270,000 ton) of total rice production in 2008 to $10 \%$ ( 470,000 ton) in 2012 
through developing various new rice-based processed foods and their commercial manufacturing technology.

Presently, the four major rice-based processed food items in domestic market are pre-cooked rice products such as retort-pouched rice and aseptic-cooked rice, rice cakes (Tteok), rice noodles, and alcoholic beverages (KRFA, 2013). Among them, manufacturing rice cakes and noodles requires rice flour as the main raw ingredient.

Use of rice as a raw material for bakery products has been limited due to its inferior performance in kneading, proofing, and baking process resulting poor eating quality of final products and higher flour milling cost compared to wheat. Purchasing price of rice and rice flour processing cost are reported to be $1.5 \sim 3$ times and $2 \sim 3$ times higher than those of wheat, respectively (Shin, 2010). Technology for rice flour milling is also far behind than wheat milling technology in many areas, such as mill equipment selection and their operating parameter determination to suit different characteristics of various wheat cultivars as well as required flour specifications for a variety of grades and end users.

For this reason, there have been needs to develop rice flour milling techniques tailored to specific food items and establish milling process of reasonable cost (Kim, 2010; Kum, 2010; Lee \& Lee, 2006a; Saito, 1980; Shin, 2009; Shin, 2010; Yoza et al., 2008). This review, therefore, aims to provide information on rice flour utilization and manufacturing with some fundamental subjects in the area of size reduction.

\section{Rice Flour Utilization for Food}

Wheat is unique in that when its flour is mixed with a limited amount of water it forms a viscoelastic dough. These viscoelastic properties enable the dough to hold the $\mathrm{CO}_{2}$ gas produced by yeast or baking powder and to expand to leavened baked products like bread with a light airy texture (Stauffer, 1998). These properties of the wheat dough are attributed to its gluten proteins. Rice has no such proteins. Hence, the production of baked goods from rice that have similar texture and eating quality to those from wheat is a real challenge (Kadan et al., 2001). Some form of hydrocolloid (water-holding biopolymer) is added invariably when rice flour is used in wheat-based baked food products. The hydrocolloid increases the viscosity of the dough and improves its gas-holding properties, and it also acts as a binder and helps to prevent the product from crumbling (Luh \& Liu, 1991).

Traditionally, rice flour has been mainly used for making rice cakes (Tteok) in Korea. But recently there has been much effort to increase rice consumption by using rice flour for not only wheat-based processed foods such as bread, noodle, cake, cookie, muffin, and pre-mix but also beverage (alcoholic and non-alcoholic), vinegar, surimi, and artificial meat (Kang et al., 1997; Kang et al., 2000; Kee et al., 2000; Kim et al., 1994; Kim, 2009; Kim \& Shin, 2009; Kum, 2011; Yang \& Kim, 2010).

Rice flour also has been found to be one of the most suitable cereal grain flours for preparing foods for celiac disease (CD) patients (Arendt and Bello, 2008). For genetically susceptible individuals, the ingestion of gluten and related proteins trigger an immune-mediated enteropathy known as celiac disease. The symptoms of CD include steatorrhea, abdominal discomfort, weight loss or gain, tiredness, anaemia, and severe diarrhea. Currently, the prevalence of CD is estimated to affect one in 100 people worldwide. The suitability of the rice flour is attributed to its low level of prolamins compared with that of wheat flour. Optimal rice bread formulations for CD patients have been developed, which meet wheat bread reference standards for specific volume, crumb and crust color, firmness and moisture (Gallagher et al., 2004).

Rice bread in its earliest stage had small amount of rice flour added to replace some wheat flour in the formula, but now bread made out of $100 \%$ rice flour is developed and sold in retail stores (Kim, 2009). The $100 \%$ rice flour bread could somewhat mislead consumers since some rice bread add up to $17 \%$ vital gluten extracted from wheat as a supplemental ingredient in their formula to improve bread-making properties; others use various food gums, emulsifiers, and enzymes, instead (Kim, 2009; Shin, 2009). Only the latter, thus, could be referred to as the so-called "gluten-free" rice bread in a strict sense.

Rice noodle product development also began with 10 $\sim 30 \%$ of rice flour and recently $100 \%$ rice flour products such as dry, wet, and extruded noodle and ramen are on the market (Kim, 2010; Shin, 2009; Yang and Kim, 2010). Rice noodle products still need to be improved concerning the processing adaptability, high loss of starch to cooking water, and eating quality (Kim, 2010; Kim et al., 2011).

There exists naming confusion between conventional rice noodle products and Vietnamese rice noodle "pho" (Ulimidan, 2013). Even though they differ in many aspects including rice variety used, processing and cooking method, 
and organoleptic characteristics, both are commonly called "rice noodle", resulting rather loose distinction between them even in food industry. There is another controversy over product definition and labeling regulation; a variety of noodle products are sold under a single name of rice noodle despite their vast differences in rice flour content. Presently, there is no clear-cut regulatory statement in Korean Food Standards Codex on this issue (Ulimidan, 2013).

\section{Rice Flour Milling}

Many terms are used interchangeably to refer to the breakdown of solid materials by the application of mechanical forces: crushing, grinding, comminution, attrition, pulverization, and milling. Among these, the term "milling" is prevalently used in grain industry such as wheat flour manufacturing. For rice, however, cautious use of the term "milling" is necessary because rice milling generally refers to the stepwise process of dehulling the paddy to make brown rice and then remove the bran layer and embryo to obtain white rice.

Difference in using "crushing" and "grinding" is commonly based on the target size of finished particles; "crushing" for coarse $(0.1 \sim 1 \mathrm{~m})$ and intermediate (1 $10 \mathrm{~cm})$ particles and "grinding" for fine $(0.1 \sim 10 \mathrm{~mm})$ and ultrafine (1 100 $\mu \mathrm{m})$ particles (Kang, 1995). Therefore, it would be reasonable to state that rice flour is produced by "grinding" brown or white rice on various types of mills or grinders.

\section{Characteristics of size reduction process}

The value of size reduction comes from (1) increasing in the surface area per unit volume which leads to more efficient processing, (2) improving mixing and blending with other materials, (3) aiding the extraction of a specific constituent from a composite material, and (4) fulfilling consumer or functional requirements for a product (Saravacos and Kostaropoulos, 2002). The principal forces of comminution are (1) compression, (2) shear, (3) friction/ abrasion/attrition, and (4) impact. Most grinders operate on a combination of these forces. Some of the most common grinding machines are hammer mills, roller mills, attrition mills (burr mills), ball mills, pin mills, and jet mills as shown in Table 1 (Kang, 1995).

Some characteristics of comminution are as follows:

(1) Theoretical analysis of mechanism is difficult; design and operation of process and plant are generally done empirically (Prasher, 1987).

(2) Energy efficiency of the process is very low; that is, as little as $1 \sim 5 \%$ of energy input may be used for actual cleavage formation and subsequent breaking (Brennan et al., 1990).

Table 1. Classification of comminution equipment (Kang, 1995)

\begin{tabular}{|c|c|c|c|}
\hline 1st classification & 2nd classification & \multicolumn{2}{|c|}{ Equipment } \\
\hline \multirow{3}{*}{ Crusher } & \multirow{4}{*}{$\begin{array}{l}\text { Coarse crusher } \\
\text { Fine crusher }\end{array}$} & \multicolumn{2}{|l|}{ Jaw crusher } \\
\hline & & \multicolumn{2}{|l|}{ Gyratory crusher } \\
\hline & & \multicolumn{2}{|l|}{ Roll crusher } \\
\hline \multirow{9}{*}{ Grinder } & & \multicolumn{2}{|l|}{ Hammer mill } \\
\hline & \multirow[t]{4}{*}{ Intermediate grinder } & \multirow{2}{*}{ Rolling-compression mill } & Bowl mill \\
\hline & & & Roller mill \\
\hline & & \multirow{2}{*}{ Attrition mill } & Burr mill \\
\hline & & & Disk mill \\
\hline & \multirow{4}{*}{ Fine grinder } & \multirow{4}{*}{ Tumbling mill } & Ball mill \\
\hline & & & Rod mill \\
\hline & & & Pebble mill \\
\hline & & & Tube mill \\
\hline \multirow{4}{*}{ Ultrafine grinder } & & \multicolumn{2}{|c|}{ Hammer mill with internal classification } \\
\hline & & \multicolumn{2}{|l|}{ Fluid-energy mill (Jet mill) } \\
\hline & & \multicolumn{2}{|l|}{ Pin mill } \\
\hline & & \multicolumn{2}{|l|}{ Agitated mill } \\
\hline
\end{tabular}


(3) Energy requirements increase substantially as the size of particle is reduced.

(4) Finished material consists of a collection of particles ranging in size; the particle size rarely assumes the well-known normal distribution.

(5) Although the maximum size of the finished material is controllable, the minimum size cannot be controlled; fines are obtained unavoidably.

(6) Compressive forces are used to fracture friable or crystalline materials, and combined impact and shearing forces are required for fibrous materials. Shearing forces are generally used for fine grinding of softer materials.

The main factors to be considered when selecting equipment for crushing and grinding are (Towler and Sinnott, 2008) (1) size of the feed, (2) size reduction ratio, (3) required particle size distribution of the product, (4) throughput, (5) material properties (hardness, abrasiveness, stickiness, density, etc), (6) permissibility of wet grinding, and (7) trade-off between capital cost and operating expenses. Some equipment selection guides are available according to the size of feed and product, reduction ratio, and material characteristics (Couper et al., 2010; Kang, 1995; Lowrison, 1974; Snow et al., 1984; Towler and Sinnott, 2008).

\section{Some theoretical aspects of comminution and grinding equations}

\section{Grinding equations}

Generalized analytical equations predicting the energy requirements for grinding different materials are few in number. In the field of agricultural engineering, the following equations have been used to relate the energy required for size reduction to the characteristic size parameters of feed and product (Guritno and Haque, 1994; Naimi et al., 2013).

$$
\begin{aligned}
& E=k_{R}\left(\frac{1}{x_{p}}-\frac{1}{x_{f}}\right) \\
& E=k_{K} \ln \left(\frac{x_{f}}{x_{p}}\right) \\
& E=k_{B}\left(\frac{1}{\sqrt{d_{p}}}-\frac{1}{\sqrt{d_{f}}}\right)=10 W_{i}\left(\frac{1}{\sqrt{d_{p}}}-\frac{1}{\sqrt{d_{f}}}\right)
\end{aligned}
$$

$$
E=a \ln \left(\frac{x_{f}}{x_{p}}\right)-b\left(\frac{1}{x_{p}}-\frac{1}{x_{f}}\right)
$$

where,

$E$ : energy required per unit mass $(\mathrm{J} / \mathrm{kg})$

$a, b, K_{R}, K_{k}, K_{B}$ : constants (-)

$W_{i}$ : Bond work index (kWh/ton), defined as the energy required to reduce a unit mass of material from a theoretical infinite size to a size such that $80 \%$ passes through $100 \mu \mathrm{m}$ sieve opening.

$x_{f}, x_{p}$ : characteristic dimensions of feed and product, respectively $(\mathrm{m})$

$d_{f}, d_{p}$ : diameters of sieve openings through which $80 \%$ of the feed and product will pass, respectively $(\mu \mathrm{m})$

In reality, none of these energy equations are applied well in practice. Due to many limitations such as extrapolation requirement and assumptions to be satisfied when using these energy laws, it is a general practice to develop empirical equations from test milling data, which relate grinding energy consumption with various operating parameters of equipment and even the properties of material (Fang et al., 1998; Gurito and Haque, 1994).

\section{Measurement and mathematical representation of particle size distribution}

There are literally dozens of techniques that are used to measure particles size (Allen, 1997) and some of them are described as follows (O'Hagan et al., 2005; Snow et al., 1984).

Sieving is probably the most frequently used and abused method because the equipment, sample preparation and analysis procedure, and basic concepts are simple and easy. Sieve analysis still assumes unique position in particle analysis; sieves test much larger amounts of sample. In essence, the statistical accuracy of data by sieving is much better than those by any other so-called state-of-the-art techniques. Sieving sizes particles in the range of 20 to $10,000 \mu \mathrm{m}$ and directly provides mass-weighted particle size distribution. Unfortunately, the use of sieves is very labor intensive. Because of this, the accuracy of the results is dependent on the skills of the operators. Furthermore, the availability of screen sizes is limited; as a result, sieving is a low-resolution technique.

The Coulter counter method involves flowing particles dispersed in a liquid through a sensing zone, across which an electric field is applied. When the particle-carrying 
liquid passes through the sensing zone, electrical characteristics in the zone change in proportion to the particle volume fraction in the passing liquid. Since the particles have short residence time in the zone, every particle produces its own electrical signal and the collected voltage pulse-height distribution is converted to a particle size distribution via a calibration curve. This technique has high resolution and sensitivity and measures particles in the range of 0.5 to about $1,500 \mu \mathrm{m}$; however, this method is limited to materials dispersible in liquids.

Light scattering methods are one of the most frequently used techniques in present laboratory studies. These methods derive particle size information from the way light interacts with a dispersion of the particles. A suspension of the particles to be characterized is placed in a measuring chamber and light is passed through the chamber and scattered by the particles in all directions. The energy distribution in the generated complex diffraction pattern is captured and transformed into particle size data by interpretive software. The signal that reaches the detector of measuring apparatus is actually a superposition of scattered light rays from many particles. These methods provide accurate distribution information but not with high resolution or high sensitivity due to this ensemble nature of the signal.

Sieving, microscopic analysis, Coulter counter, and light diffraction are frequently used methods of rice flour particle size measurement. Measurement results were varied depending on the technique used. (Kim and Kim, 1994; Kum et al., 1993a). Kum et al. (1993a) reported that fine rice flour particles were agglomerated during sieving and became unable to pass through sieve openings; then, they caused an inaccurate measurement. Hareland (1994) suggested that the particle size distribution of wheat flour could be measured more precisely by laser diffraction method than by sieve analysis.

There are a number of mathematical expressions which have been proposed to describe particle size distribution and to correlate cumulative quantity of particles with particle size. Some frequently used expressions are (ASAE, 2003; Kang, 1995; Lowrison, 1974; Prasher, 1987; Snow et al., 1984):

(1) Log-normal distribution

$$
f(x)=\frac{1}{x \sigma \sqrt{2 \pi}} \exp \left[-\frac{(\ln x-\mu)^{2}}{2 \sigma^{2}}\right] ; \phi(x)=\frac{1}{2}+\frac{1}{2} \operatorname{erf}\left[\frac{\ln x-\mu}{\sqrt{2 \sigma^{2}}}\right]
$$

(2) Rosin-Rammler-Bennett equation

$$
f(x)=m\left(\frac{x^{m-1}}{x_{R R B}^{m}}\right) \exp \left[-\left(\frac{x}{x_{R R B}}\right)^{m}\right] ; \phi(x)=1-\exp \left[-\left(\frac{x}{x_{R R B}}\right)^{m}\right]
$$

(3) Gates-Gaudin-Schuhmann equation

$$
f(x)=\frac{n x^{n-1}}{x_{G G S} n} ; \quad \phi(x)=\left(\frac{x}{x_{G G S}}\right)^{n}
$$

(4) Gaudin-Meloy equation

$\phi(x)=1-\left(1-\frac{x}{x_{G M}}\right)^{r}$

where,

$\phi(x)$ : cumulative fraction by weight undersize (decimal) $f(x)$ : particle size distribution on weight basis (decimal) $x$ : particle size (mm or $\mu \mathrm{m}$ )

${ }_{R R B}{ }_{R}{ }^{x_{G G S},{ }^{x} G M}$ : parameters with dimension of size ( $\mathrm{mm}$ or $\mu \mathrm{m}$ )

$m, n, r:$ parameters for exponent $(-)$

$\mu, \sigma$ : mean and std. deviation of particle size distribution for $x$, respectively ( $\mathrm{mm}$ or $\mu \mathrm{m}$ )

erf: error function

\section{Rice flour manufacturing process}

Rice flour is produced from whole or broken kernels of brown or white rice. Depending on specific end use, both waxy and non-waxy type rice are used in flour milling. Four different methods are presently available for rice flour milling although most of domestic rice flour is either dry-milled or wet-milled (Table 2).

Dry milling is simple and straightforward; rice kernels are milled into dry flour whose moisture is about $10 \%$ without any preprocessing. Dry-milled rice flour has some starch damage because substantial heat is generated during milling.

In wet milling, rice is first soaked in water for an extended period of time to make its internal structure better conditioned for subsequent milling. Small-scale or household rice milling for flour or coarse meal and grit to make traditional rice dishes is mostly done when the rice is well hydrated. Wet-milled rice flour usually produces better texture and finer particles of a narrow size distribution with less damaged starch than dry-milled flour (Chen et al., 1999). However, specific energy consumption becomes higher due to finishing drying and additional equipment 


\begin{tabular}{|c|c|c|}
\hline Method & Procedure & Reference \\
\hline Dry & Milling & \\
\hline Wet & Soaking - Dewatering - Milling - Drying & \\
\hline Semi-wet & Spraying - Dewatering - Milling - Drying & \multirow{3}{*}{$\begin{array}{c}\text { Lee (2002) } \\
\text { Shin et al. (2007) } \\
\text { Koh (2013) }\end{array}$} \\
\hline \multirow{2}{*}{ Misc. } & Soaking - Drying ${ }^{\text {a) }}$ - Milling & \\
\hline & Water spraying - Tempering - High pressure treatment - Milling & \\
\hline Two-step & Washing - Soaking - Dewatering $-1^{\text {st }}$ Roller milling $-2^{\text {nd }}$ Jet milling-Drying & \multirow{2}{*}{ Yoshii (2011) } \\
\hline Enzyme-treated & Washing - Enzyme treatment - Jet milling - Drying & \\
\hline
\end{tabular}

${ }^{a}$ Gentle drying such as ambient air, low-temp. air, or vacuum drying.

is required for preprocessing. In addition, some watersoluble components are lost during soaking stage; thus, wastewater treatment is necessitated (Kum, 2010; Shin, 2009). In semi-wet milling, rice kernels get water-sprayed on their surface for shorter period of time than watersoaked time of wet milling (Kum, 2010; Lee, 2002).

Average size of rice flour commercially produced by roller mill ranges $80 \sim 120$ mesh $(125 \sim 177 \mu \mathrm{m}$ ) (Kum, 2010; Park et al., 2006). Recently, however, ultrafine rice powder down to 500 mesh has gained attention and rice flour utilization is explored in many new products (Kum, 2010). Characteristics and quality of rice flour are influenced by many factors such as rice cultivar (Han et al., 2012), preprocessing method (Chiang and Yeh, 2002; Kim and Kim, 1995), milling method (Choi et al., 2006; Lee \& Lee, 2006b) and equipment (Kum et al., 1993a; Park et al., 1988), and particle size distribution (Kum and Lee, 1999; Park et al., 2006). It is now generally accepted that particle size distribution and degree of damaged starch are the two key factors affecting the physicochemical properties of rice flour and in turn the suitability of the flour for specific application.

Research work to establish rice flour milling process tailored to different flour applications is at early stage in Korea. Japanese researchers, with the aim of replacing wheat flour use with rice flour by more than $10 \%$, have been developing such purpose-specific rice flour milling methods since 1970s (Funatsuki, 2011; Kim, 2010; Yoza, 2008).

The type of milling equipment profoundly affects the physical and functional properties of the rice flour (Kum et al., 1993a, 1993b; Nishita and Bean, 1982; Park et al., 1988). A variety of millers have been used in rice flour milling both at laboratory experiments and rice flour manufacturing plants (Kum et al., 1993a; Nishita and
Bean, 1982; Park et al., 1988). Some of them are shown in Figure 1.

A hammer mill consists essentially of a high-speed rotor and a sturdy perforated screen. The feed material is introduced into the housing and the rotor which has several equally-spaced hammers at its periphery pounds the material until it is small enough to pass through the screen at the bottom of the equipment housing.

The roller mill (Fig. 1 (a)) is the principal equipment in commercial wet milling of rice flour. In a roller mill, a pair of horizontal steel rollers revolves toward each other, pulls the feed material into a narrow gap between them, and grinds the material into powder through compression and shearing action. Roller surfaces are smooth, fluted, or corrugated and there may be speed differential between two rollers.

A pin mill (Fig. 1 (b)) consists of two disks upon each of which concentric rows of metallic pins, pegs, or teeth are attached, of such radii that the rows of one disk fit alternatively into the rows of the other disk. One disk rotates and the other is either stationary or rotates also. The material is fed axially, passes through in the radial direction, and is ground through impacting and attrition (Lowrison, 1974).

A jet mill (Fig. 1 (c)) generates a supersonic air current by blowing pressurized air supplied by a compressor through a supersonic nozzle. The feed particles that injected into air jet stream are accelerated and crushed by collision with an impact plate and also with other particles. The ground particles are sent to a classifier where fine particles are separated from large ones and pneumatically sent to and captured by a cyclone. The large particles are returned to the jet mill from the classifier and pulverized again until they are crushed to a size small enough to be separated by the classifier (Hossen et 


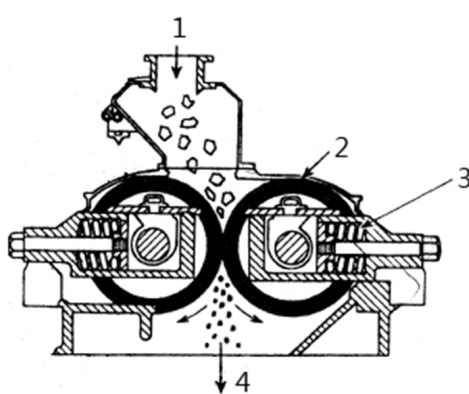

(a)

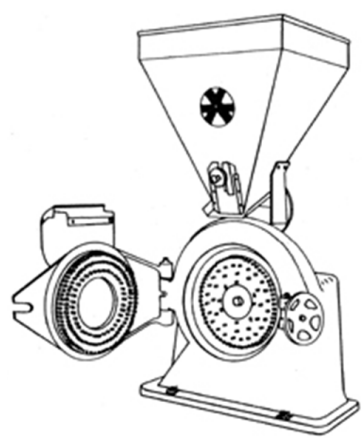

(b)

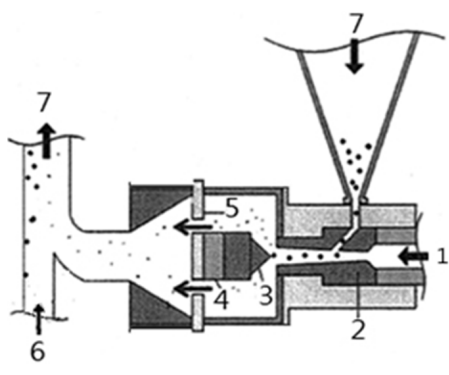

(c)

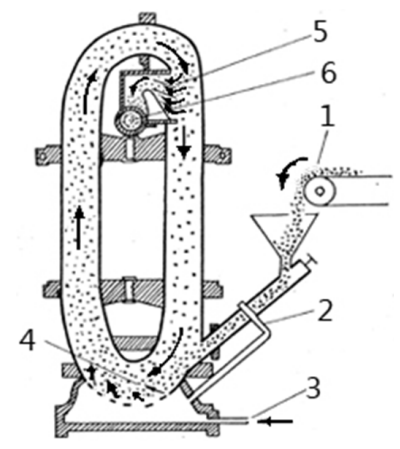

(d)

Figure 1. Three major millers used for rice flour production (Beke, 1981; Couper et al., 2010; Hossen et al., 2011; Snow et al., 1984). (a) Roller mill (1: feed, 2: roller, 3: relief spring, 4: discharge); (b) Pin mill; (c) Fluid-energy mill (1: compressed air, 2: nozzle, 3: impact plate, 4: adjust ring for impact plate, 5: impact plate upholder, 6: from feeder, 7: to and from cyclone classifier); (d) Fluid-energy mill (torus type) (1: feeder, 2: injector, 3: compressed air, 4: breakage chamber, 5: classifying zone, 6: outlet).

al., 2011).

In a torus type jet mill (Fig. 1 (d)), material is fed into a central toroidal chamber and is driven at near sonic velocity around the perimeter of the chamber by multiple jets of air or steam. The particles continue to circulate in the chamber until they are sufficiently ground; then, they migrate toward the central discharge port and exit the chamber. Size reduction in this type of jet mill is the result of the high-velocity collision between particles of the process material itself (Beke, 1981). Jet mills have low energy efficiency compared to other mills, but the air flow minimizes heat generation during milling and eliminates thermal degradation of starch in the rice flour produced (Suh et al., 2004).

\section{Conclusions}

This review aims to provide information on rice flour utilization and manufacturing with some fundamental subjects in the area of size reduction.

Technology for rice flour milling is far behind than wheat milling technology in areas such as mill equipment selection and their operating parameter determination to suit different characteristics of various wheat cultivars as well as required flour specifications for a variety of grades and end users.

A variety of food items including bread, noodle, cake, cookie, muffin, pre-mix, beverage, vinegar, surimi, and artificial meat have found rice flour as their raw ingredient. Rice bread in its earliest stage had small amount of rice flour added to replace some wheat flour in the formula, but now bread made out of $100 \%$ rice flour is developed and sold in retail stores. Rice noodle product development began with $10 \sim 30 \%$ of rice flour and recently $100 \%$ rice flour products are on the market although they still need to be improved with respect to processing adaptability, turbidity, and eating quality.

There are pending issues regarding product definition and labeling; a variety of noodle products are sold under the name of rice noodle despite the vast differences in rice flour content. Presently, there is no clear-cut regulatory statement in Korean Food Standards Codex on this.

The statistical accuracy of particle size measured by sieving is much better than those by other techniques but the accuracy of the results is often dependent on the skills of the operators. Light diffraction method is convenient to use and provides accurate particle size measurement but not with high resolution or high sensitivity due to the inherent ensemble nature of the signal.

Particle size distribution and degree of damaged starch are the two key factors affecting the physicochemical properties of rice flour and in turn the suitability of the flour for specific application. Type of milling equipment profoundly affects functional properties of rice flour. Hammer, roller, pin, and jet mill are mostly used for rice flour milling both at laboratory experiments and manufacturing plants.

\section{Conflict of Interest}

The author has no conflicting financial or other interests. 


\section{References}

Allen, T. 1997. Particle Size Measurement, vol. 1. London, England: Chapman \& Hall.

Anonymous. 2012. Food, Agriculture, Forestry and Fisheries Statistical Yearbook 2012: Ministry for Food, Agriculture, Forestry and Fisheries, Rep. of Korea (In Korean).

Arendt, E. K. and F. D. Bello. 2008. Functional cereal products for those with gluten intolerance. In: Technology of Functional Cereal Products, ed. B. R. Hamaker. Cambridge, England: Woodhead Publishing Ltd. 446475.

ASAE Standards. 2003. S319.3: Method of Determining and Expressing Fineness of Feed Materials by Sieving. St. Joseph, MI: ASAE.

Beke, B. B. 1981. The Process of Fine Grinding. Hingham, MA: Kluwer Boston Inc.

Brennan, J. G., J. R. Butters, N. D. Cowell and A. E. Lilly. 1990. Food Engineering Operations. London, England: Elsevier Applied Sci.

Chen, J. J., S. Lu and C. Y. Lii. 1999. Effect of milling on the physicochemical characteristics of waxy rice in Taiwan. Cereal Chemistry 76(5):796-799.

Chiang, P. Y. and A. I. Yeh. 2002. Effect of soaking on wet-milling of rice. J. of Cereal Science 35:85-94.

Choi, B. K, J. S. Kum, H. Y. Lee and J. D. Park. 2006. Physicochemical properties of black rice flour affected by milling conditions. Kor. J. Food Sci. \& Technol. 38(6):751-755 (In Korean, with English abstract).

Couper, J. R., W. R. Penney, J. R. Fair and S. M. Wallas. 2010. Chemical Process Equipment. Burlington, MA: Butterworth-Heinemann 364-376.

Fang, Q., E. Haque, C. K. Spillman, P. V. Reddy and J. L. Steele. 1998. Energy requirements for size reduction of wheat using a roller mill. Transactions of the ASAE 41(6):1713-1720.

Funatsuki, W. 2011. Processing technologies for high quality rice flour in Japan. Proceedings of the KoreaJapan Joint Seminar on Development of Rice Processing Technology 169-200.

Gallagher, E., T. R. Gormley and E. K. Arendt. 2004. Recent advances in the formulation of gluten-free cereal-based products. Trends in Food Sci. \& Technol 15:143-152.

Guritno, P. and E. Haque. 1994. Relationship between energy and size reduction of grains using a three-roller mill. Transactions of the ASAE 37(4):1243-1248.
Han, H. M., J. H. Cho and B. K. Koh. 2012. Effect of grinding method on flour quality in different rice cultivar. J. Kor. Soc. Food Sci. Nutr. 41(11):1596-1602 (In Korean, with English abstract).

Hareland, G. A. 1994. Evaluation of flour particle size distribution by laser diffraction, sieve analysis and near-infrared reflectance spectroscopy. J. of Cereal Sci. 21:183-190.

Hossen, Md. S, I. Sotome, M. Takenaka, S. Isobe, M. Nakajima and H. Okadome. 2011. Starch damage and pasting properties of rice flours produced by dry jet grinding. Cereal Chemistry 88(1):6-11.

Kadan, R. S., M. G. Robinson, D. P. Thibodeaux and A. B. Pepperman Jr. 2001. Texture and other physicochemical properties of whole rice bread. J. of Food Sci. 66(7): 940-944.

Kang, S. H. 1995. Powder Technology. Seoul, Korea: Hee Joong Dang Publishers (In Korean).

Kang, M. Y., Y. H. Choi and H. C. Choi. 1997. Effects of gums, fats and glutens adding on processing and quality of milled rice bread. Kor. J. Food Sci. \& Technol. 29(4): 700-704 (In Korean, with English abstract).

Kang, M. Y., H. J. Koh and J. Y. Han. 2000. Comparison of some characteristics relevant to rice bread made from eight varieties of endosperm mutants between brown and milled rice. Kor. J. Food Sci. \& Technol. 32(1):82-89 (In Korean, with English abstract).

Kee, H. J., S. T. Lee and Y. K. Park. 2000. Preparation and quality characteristics of Korean wheat noodles made of brown glutinous rice flour with and without aroma. Kor. J. Food Sci. \& Technol. 32(4):799-805 (In Korean, with English abstract).

Kim, Y. J. and S. S. Kim. 1994. Comparison of size distributions of rice flour measured by microscopic, sieve, coulter counter, and aerodynamic methods. Kor. J. Food Sci. \& Technol. 26(2):184-187 (In Korean with, English abstract).

Kim, S. S., Y. J. Kim and Y. J. Lee. 1994. Effects of waxy rice flours on rice muffins containing various combinations of nonwaxy/waxy rice flour. Foods \& Biotechnol. 3(2):57-59.

Kim, S. S. and Y. J. Kim. 1995. Effect of moisture content of paddy on properties of rice flour. Kor. J. Food Sci. \& Technol. 27(5):690-696 (In Korean, with English abstract).

Kim, S. S. 2009. Development of novel rice bakery products with high quality. Research report. Kyonggi-do, 
Korea: Korea Food Research Institute (In Korean).

Kim, J. N. and W. S. Shin. 2009. Physical and sensory properties of chiffon cake made with rice flour. Kor. J. Food Sci. \& Technol. 41(1):69-76 (In Korean, with English abstract).

Kim, T. H. 2010. Rice processing industry and product status. Food Preservation and Processing Industry 9(1):86-96.

Kim, B. K., J. E. Park and G. Zu. 2011. Effects of semolina on quality characteristics of the rice noodles. Food Engineering Progress. 15(1):56-63 (In Korean with, English abstract).

Koh, H. J. 2010. Current status of rice production, distribution, processing and utilization in Korea. Food Preservation and Processing Industry 9(2):21-31.

Koh, B. K. 2013. Dry milling method of rice flour with reduced starch damage. Korean Patent No. 10-20130029287 (In Korean).

KRFA (Korea Rice Foodstuffs Association). 2013. Types of processed rice foods in Korea. Seoul, Korea: The Korea Rice Foodstuffs Association. Available at: www. krfa.or.kr (In Korea).

Kum, J. S., S. H. Lee, H. Y. Lee, K. H. Kim and Y. I. Kim. 1993a. Effect of different milling methods on distribution of particle size of rice flours. Kor. J. Food Sci. \& Technol. 25(5):541-545 (In Korean, with English abstract).

Kum, J. S., S. H. Lee, H. Y. Lee, K. H. Kim and Y. I. Kim. 1993b. Effect of different milling methods on physicochemical properties and products. Kor. J. Food Sci. \& Technol. 25(5):546-551 (In Korean, with English abstract).

Kum, J. S. and H. Y. Lee. 1999. The effect of the varieties and particle size on the properties of rice flour. Kor. J. Food Sci. \& Technol. 31(6):1542-1548 (In Korean, with English abstract).

Kum, J. S. 2010. Rice consumption increase through technological improvement in rice processing. Food Preservation and Processing Industry 9(2):49-59.

Kum, J. S. 2011. Study on processing technology and product development for exportation of traditional rice product. Research report. Kyonggi-do, Korea: Korea Food Research Institute (In Korean).

Lee, H. Y. 2002. A study on the development of semi-wet rice flour. Research report. Kyonggi-do, Korea: Korea Food Research Institute (In Korean).

Lee, M. H. and Y. T. Lee. 2006a. Properties of gluten-free rice breads using different rice flours prepared by dry, wet and semi-wet milling. Food Engineering Progress.
10(3):180-185 (In Korean with, English abstract).

Lee, M. H. and Y. T. Lee. 2006b. Bread-making properties of rice flours produced by dry, wet and semi-wet milling. Kor. J. Food Sci. \& Technol. 35(7):886-890 (In Korean, with English abstract).

Leluschko, J. 1989. Crushing and Grinding Process Handbook. Von CL Prasher. John Wiley \& Sons Ltd., Chichester-New York 1987. XII, 474 S., zahlr. Abb. u. Tab., geb.,£ 49. Chemie Ingenieur Technik, 61(1), 96-96.

Lowrison, G. C. 1974. Crushing and Grinding. London, England: Butterworth \& Co. Ltd.

Luh, B. S. and Y. K. Liu. 1991. Rice flours in baking. Rice Utilization 9-33.

Naimi, L. J., S. Sokhansanj, X. Bi, C. J. Lim, A. R. Womac, A. K. Lau and S. Melin. 2013. Development of size reduction equations for calculating energy input for grinding lignocellulosic particles. Applied Eng. in Agri. 29(1): 93-100.

Nishita, K. D. and M. M. Bean. 1982. Grinding methods: their impact on rice flour properties. Cereal Chemistry 59(1):46-49.

O'Hagan, P., K. Hasapidis, A. Coder, H. Helsing and G. Pokrajac. 2005. Particle size analysis of food powders. Encapsulated and Powdered Foods 215-245.

Park, Y. K., H. M. Seog, Y. J. Nam and D. H. Shin. 1988. Physicochemical properties of various milled rice flours. Kor. J. Food Sci. \& Technol. 20(4):504-510 (In Korean, with English abstract).

Park, M. K., K. H. Lee and S. A. Kang. 2006. Effect of particle size of rice flour on popping rice bread. Kor. J. Food Cookery Sci. 22(4):419-427 (In Korean, with English abstract).

Perry, R. H., Green, D. W., \& Maloney, J. O. 2008. Perry's chemical engineers' handbook (7). New York: McGrawHill.

Saito, S. 1980. Rice starch and rice powder as materials for food industry. J. of Jap. Soc. Starch Science 27(4): 295-313 (In Japanese).

Saravacos, G. D., \& Kostaropoulos, A. E. 2002. Handbook of food processing equipment. Springer.

Shin, M., D. O. Gang and Y. H. An. 2007. Preparation methods for rice flour mixes and rice bread. Korean Patent No. 10-0742572 (In Korean).

Shin, M. 2009. Rice-processed food. Food Science and Industry 42(4):2-18 (In Korean).

Shin, M. 2010. Revitalizing rice processing industry to 
lead the food industry of upcoming green growth. Food Preservation and Processing Industry 9(1): 16-37.

Stauffer, C. E. 2007. Principles of dough formation. In Technology of breadmaking. Springer US 299-332.

Sinnott, R. K., \& Towler, G. 2009. Chemical Engineering Design: SI Edition. Butterworth-Heinemann.

Suh, T. S., G. Lee, Y. K. Seo, K. P. Lee and D. J. Kim. 2004. Micro particle technology in food science. Food Science and Industry 37(4):17-21 (In Korean).

Ulimidan. 2013. Company Web Site. Available at: www. ulinala.com.
Yang, H. S. and C. S. Kim. 2010. Quality characteristics of rice noodles in Korean market. J. Kor. Soc. Food Sci. Nutr. 39(5):737-744 (In Korean, with English abstract).

Yoshii, Y., N. Homma and R. Akaishi. 2011. Development of rice processing technology in Niigata Prefecture. J. Jap. Soc. for Food Science and Technology 58(5):187195 (In Japanese).

Yoza, K., M. Okabe and J. Shima. 2008. Present status and issues of rice powder utilization: rice bread. J. Jap. Soc. for Food Science and Technology 55(10):444-454 (In Japanese). 